\title{
Relações entre urbanização e meio ambiente: um panorama para os estados brasileiros
}

Relations between urbanization and environment: an overview for the Brazilian states

\author{
Rosa Livia Gonçalves Montenegro \\ rosalivia@gmail.com \\ Universidade Federal de São João del Rei (UFSJ)
}

Resumo: A discussão sobre os problemas urbanos e as mudanças ambientais vividas pela população brasileira, em especial nas grandes cidades, é bastante atual e sugere mais pesquisas a respeito do assunto. Dessa forma, a proposta deste trabalho será analisar os efeitos de três dimensões (socioeconômica, demográfica e ambiental) que estão associadas, de alguma forma, ao processo de urbanização no Brasil. Para tanto, utilizaram-se como unidades de observação os vinte e sete estados brasileiros sendo aplicadas na metodologia da análise de componentes principais (ACP), e na análise de cluster. A proposta metodológica pretende caracterizar os estados mediante as variáveis selecionadas no trabalho. Os resultados mostraram disparidades entre as regiões e seus aspectos infraestruturais e ambientais, além da forte tendência na criação de áreas urbanas periféricas em algumas regiões, o que aumentará em longo prazo, os impactos ambientais nesses locais.

Palavras-chave: Urbanização; Indicadores ambientais; Estados brasileiros; Análise multivariada

\begin{abstract}
The discussion about urban problems and environmental changes faced by the population, especially in large cities, is very current and it suggests further research on the issues. Thus, the main aim of this paper is to analyze the effects on three dimensions (socioeconomic, demographic and environmental), which are associated with urbanization process. With database of Brazilian states, this paper applies a set of methodological techniques: a) Principal Component Analysis (PCA) and b) Cluster Analysis. The main results indicate the differences among the Brazilian States, including in infrastructural and environmental aspects. Moreover, the results also show a tendency of expanding peripheral urban areas in the States, which could increase the environmental impacts in the long run.
\end{abstract}

Keywords: Urbanization; Environmental indicators; Brazilian states; Multivariate analysis

\section{INTRODUÇÃO}

Os estudos sobre a contextualização da urbanização voltada para questões ambientais vêm ganhando destaque na literatura da área (CUI e SHI, 2012; CHADCHAN e SHANKAR, 2009; HOPE, 1986; KALNAY e CAI, 2003). Paralelamente a essa discussão encontra-se o debate entre a questão do desenvolvimento econômico-tecnológico e seus impactos ambientais (CARRILLOHERMOSILLA et al., 2010; KEMP e SOETE, 1992; HORBACH, RAMMER e RENNINGS, 2014). A atenção dos estudiosos se volta para os problemas ambientais que são afetados pelas 
mudanças tecnológicas (produtos que agridem o meio ambiente), os impactos de dimensão local e regional (por exemplo, qualidade do ar) que passaram a ter uma dimensão global (aumento do efeito estufa e o aquecimento global).

O aumento contínuo da produção, associado ao crescimento da população, irá requerer no futuro maior quantidade de recursos naturais, implicando no aumento de rejeitos no meio ambiente. Barret (2009), por exemplo, alerta sobre as limitações impostas ao funcionamento do mercado pelos problemas contemporâneos relacionados às mudanças climáticas. Nesse ponto, o conceito de sustentabilidade tem retomado discussões importantes sobre os impactos negativos ambientais. Segundo Bellen (2005) e WCED (1987), o termo sustentabilidade abrange um conceitual amplo e ao mesmo tempo complexo, o qual caracteriza um conjunto de ações das sociedades contemporâneas que atende às necessidades do presente sem comprometer a possibilidade de gerações futuras atenderem às suas próprias.

No caso brasileiro, há uma grande lacuna entre seu processo de crescimento econômico e o termo sustentabilidade. O primeiro ponto que deve ser ressaltado é que, graças a um conjunto de políticas macroeconômicas e sociais, o país tem reduzido as taxas de pobreza e desigualdade. Esse resultado positivo fomenta o aumento do consumo em classes como a "C" e "D", que por sua vez, proporciona um maior acesso dos mercados de bens e serviços. Nesse sentido, o crescimento de consumidores potenciais, não somente no Brasil, mas também em escala global, é um risco ambiental de médio e longo prazo. Sobre essa temática surgem diversas questões complexas, como por exemplo, a redução do consumo de países ricos e emergentes e a diminuição das taxas de pobreza sem que haja um aumento das emissões de carbono.

Diante dessa problemática, a questão da urbanização é um elemento que também deve ser discutido e levado em consideração, principalmente, devido ao crescimento populacional e seus reflexos nos déficits infraestruturais e de serviços. Uma das soluções para os grandes centros urbanos, a médio e longo prazo, seria a implementação da ideia das cidades "sustentáveis", o que demandaria uma grande parcela de investimentos, além de planejamento urbano e territorial. A proposta seria uma alternativa para as cidades não focarem apenas em soluções rigorosamente econômicas. Além disso, a produção e a absorção social dos espaços urbanos podem gerar condições propícias para o surgimento de novos padrões de produção mais sustentáveis, como o uso sustentável de fontes de energia e de logística (NAKANO e CUNHA, 2012).

A proposta do presente artigo, a partir da metodologia de análise de componentes principais (ACP) e análise de cluster, têm por objetivo caracterizar os efeitos proporcionados por diferentes fatores referentes às questões urbanas e do meio ambiente. Deste modo, busca-se analisar a partir de 
três dimensões (socioeconômicas, demográficas e ambientais) quais as caracterizações existentes nos 27 Estados brasileiros, no período entre 2008 e 2010.

Além dessa introdução, o artigo organiza-se em mais sete tópicos. Nos dois próximos tópicos serão discutidos a questão espacial e os modos de integração econômica, apresentando suas principais corrente teóricas. No terceiro item serão abordados alguns aspectos sobre o processo de urbanização e sustentabilidade no Brasil. Em seguida, será discutida a proposta metodológica. Nos itens posteriores serão apresentadas as descrições dos resultados e as principais conclusões do trabalho.

\section{A CONFIGURAÇÃO DO ESPAÇO E SUAS DIVERSAS INTERRELAÇÕES}

As novas abordagens sobre as questões de economia, política e espaço discutem os atuais problemas da sociedade e procuram unificar os vários campos de análise urbana e espacial compreendendo essa relação com o Estado. A análise segue além da interseção espacial dos processos políticos e econômicos e, também, avança no sentido de compreender que a dispersão regional depende das forças sociais. De modo geral, as pesquisas relacionadas ao urbano versus o espaço estudam os problemas econômicos, políticos e sociais que são influenciados por uma perspectiva espacial, baseada nos padrões de localização.

Nesse contexto, Lipietz (1987) procura desenvolver uma reflexão sobre o significado do espaço e das relações que este proporciona com o modo de produção capitalista. O autor faz uma crítica sobre a concepção empírica do espaço, assim como, da conjuntura regional. Em seu respectivo trabalho, observa-se uma forte necessidade de articular as relações sociais, na medida em que se tem uma dimensão espacial polarizadora. Além disso, Lipietz (1987) analisa as relações sociais que existem entre a divisão interregional e as mudanças na divisão internacional do trabalho.

Sua concepção sobre o pensamento marxista é clara, e enfatiza a discussão do modo de produção capitalista e seus desdobramentos espaciais e impactos no plano das relações sociais. Segundo o autor, o espaço social é estruturado pelo capital e a pela estratégia de localização é definida pelos interesses privados. É válido ressaltar que a caracterização do espaço também apresenta o Estado como detentor da organização territorial, e que traz consigo problemas que não se resolvem no plano de mecanismos de mercado.

De acordo com Santos (1994), toda relação contemporânea é suscetível a diferentes temporalidades, sendo elas hegemônicas ou hegemonizadas. Isso significa dizer que, o espaço é intimamente relacionado com o tempo, se globaliza, assim como as pessoas e os lugares. As dimensões mundiais, segundo o autor, são as instituições ditas mundiais. Entretanto, o mundo da 
globalização é contrariado no próprio lugar, seja sua configuração territorial, organização ou seus regimes de regulação que se formam simultaneamente e de maneira independente.

Santos (1994) também fornece detalhes sobre as técnicas que, podem ser visualizadas ou não em uma paisagem, contudo, são dados explicativos do espaço. As técnicas abordadas pelo autor não possuem a mesma idade e se efetivam em relações concretas conduzindo-as sobre a noção de modo de produção e de relação de produção. Em qualquer ponto do espaço, cada elemento revela uma técnica ou tem em um conjunto de técnicas particulares, sendo que cada um desses elementos possuem a dependência dessas técnicas. O conjunto de temporalidades próprias a cada ponto do espaço, não é fornecido por nenhuma técnica, mas sim, pelo conjunto de técnicas existentes naquele ponto do espaço.

Na verdade, Santos (1994) consegue abordar diversos aspectos do sistema de ação e da dinâmica espacial que ocorrem nas cidades. O autor define o espaço como um lugar onde pode ser enfocado como a "reunião" dialética de fluxos, isto é, um conjunto contraditório sendo constituídas por uma configuração territorial e por relações de produção, relações sociais, sistema de objetos e de ações.

Em suma, a crítica dos autores (Santos, 1994; Lipietz, 1987) sobre o aspecto da economia política dentro do contexto espacial seria justamente a contradição do modo de produção capitalista que procura sobreviver e refletir ao longo do seu desenvolvimento a partir dos mecanismos da reprodução do espaço. Entretanto, quanto mais o espaço é aproximado para o núcleo do capitalismo, maior será a importância da configuração do espaço dentro do âmbito capitalista. O pensamento crítico converge para os conflitos e contradições sociais existentes no mundo contemporâneo, no qual articula os agentes produtores do espaço em todos os níveis e dimensões da realidade social, a partir da escala mundial até as cidades.

\section{OS DIVERSOS MODOS DE INTEGRAÇÃO ECONÔMICA E O NOVO CONTEXTO SOCIAL}

A corrente econômica globalizada baseia-se, principalmente, na centralidade das economias mundiais como instrumentos reguladores dos fatores significativos mediante as economias nacionais. De modo geral, há uma formação do novo espaço econômico abstrato, capaz de se potencializar e, ao mesmo tempo, subordinar-se a determinação de uma economia mundial cada vez mais dominada por diferentes interesses, sejam eles estatais ou privados. 
A contextualização da nova ordem sociológica econômica fundamenta-se nas novas relações sociais e, dita de outra forma, sobre os limites impostos pela competição internacional, mecanismos propostos no contexto da acumulação capitalista mundial. Segundo Vinha (2001), a sociologia econômica de Polanyi e a Nova Sociologia Econômica (NSE) procuram integrar as teorias sociológicas e econômicas. Ao mesmo tempo, diferenciam-se das demais correntes de pensamento das ciências sociais por privilegiar a dimensão histórica e os estudos empíricos, além de fornecer argumentos críticos consistentes com a teoria neoclássica. A NSE é baseada na ideia de que a economia e a sociedade são mutuamente enraizadas, apontando caminhos para superar as deficiências explicativas da teoria neoclássica.

A economia na visão de Polanyi é constituída pela sinergia entre o homem e o seu ambiente. Entretanto, fatores sociais e elementos constituintes dos processos tecnológicos, ecológicos, não interagiriam e seriam interdependentes. A dinâmica econômica interligada por fatores institucionais econômicos e não econômicos funcionaria em um mecanismo instituído por diferentes espaços de tempo e lugares. Deste modo, existem diferenças entre o modo de absorção e/ou manifestação desses intercâmbios e também das diferentes formas de integração.

Um dos aspectos importantes discutido por Vinha (2001) está relacionado às características da firma. Atualmente, as firmas preocupadas e focadas em atingir suas estratégias de responsabilidade social, de acordo com seu perfil, estariam mais propensas em implementar projetos focados em gestão ambiental e também voltados as ações comunitárias. Contudo, algumas questões não estariam totalmente esclarecidas com relação a essas empresas, como as que seguem: Quais seriam as relações entre empresas e as ações voltadas à comunidade? Quais as formas de articulação entre esses agentes e como funcionaria a coordenação entre ambos?

A resposta para as questões levantadas acima, segundo a NSE, estaria pautada na relação com os grupos que atuam na área de influência entre a empresa e seus objetivos em prol do enraizamento social. Por outro lado, as redes de relações sociais exigiriam por parte das empresas um comportamento das firmas inspirado em garantias, credibilidade, enfim, elementos baseados na integração econômica entre ambos os agentes.

$\mathrm{O}$ argumento para o uso e o estabelecimento dessas redes, contudo, podem ser fundamentados pelos pontos discutidos na NSE. Entre os principais pontos está o fato de que a empresa precisa construir uma estratégia, principalmente pata satisfazer simultaneamente compradores, ambientalistas, consumidores e a comunidade. O segundo ponto seria a busca pelas empresas de um modelo organizacional capaz de promover àquelas que adotam as melhores práticas e, além disso, conseguem atingir um aumento na sua produtividade e a obtenção de lucros extraordinários. Observa-se, portanto, que a NSE compartilha um novo paradigma, principalmente a 
respeito do lugar dos atores na mudança social, com a fronteira entre ciência e valor, e com as relações entre o que se diferencia da economia e do social (LÉVESQUE, 2007).

Todos esses elementos que constituem o enraizamento social praticado pelas empresas convergem para a incessante busca da regularidade e da reciprocidade, e que envolve, além disso, as relações de poder tais como hierarquia e controle. Para Lévesque (2007), a economia e a sociedade estariam ainda mais interligadas nos dias atuais e, com isso, as próprias transformações econômicas possuem a necessidade de maiores intervenções sociais. O autor ainda afirma que o neoliberalismo contribuiu para a reconstrução da sociedade civil. No entanto, tais transformações socioeconômicas não eliminaram a necessidade de intervenções governamentais.

De modo geral, o que se pode inferir desse relacionamento entre empresas e sociedade seria uma dinâmica econômica voltada para um mercado auto-regulável. Isto significa dizer que as relações entre reciprocidade e redistribuição estariam voltadas para um modelo de autocoordenação regulado pelo próprio mercado.

As transformações que vem ocorrendo no ambiente econômico que, segundo a NSE, se denomina como um processo de desenvolvimento sustentável baseado em quatro vetores fundamentais. O primeiro vetor está relacionado ao questionamento social, isto é, uma forte discussão sobre o sistema capitalista e as rupturas intrínsecas desse sistema, no que tange ao processo cultural e artístico. Já o segundo vetor, revela a dependência de uma globalização financeira, que fortalece e promove novas fontes de desigualdades econômicas. O terceiro vetor é caracterizado pelas novas tecnologias de informação e comunicação (TIC), inclusive fomentando a interdependência entre os elementos econômicos e sociais. No último vetor, é questionado o risco presente na sociedade, isto é, focando-se mais na inserção e na prática de um desenvolvimento sustentável.

A perspectiva, entretanto, seria a compreensão cada vez maior da dimensão social da economia. De certa forma, os fatores sociais e os elementos sustentáveis são amplos e devem ser estudados e sentido somente em longo prazo, em virtude da sua difícil construção social e seus paradigmas sociais predominantes (LÉVESQUE, 2007).

Destarte, o que se pode concluir a respeito dos modos de integração econômica e as alternativas para a organização socioespacial é que não há um consenso sobre as diversas formas de organização. As interações sociais podem ser mais bem articuladas, isto é, a discussão sobre o argumento da NSE deveria ser feita no ponto de seu total esgotamento, principalmente a favor de um desenvolvimento sustentável mais efetivo. 


\subsection{O avanço no processo de urbanização: limitações e desafios para o Brasil}

$\mathrm{Na}$ atualidade, uma das mais importantes unidades geográficas, que não seja a própria nação, são as áreas urbanas. Em todos os países do mundo, mais da metade da renda advém das áreas urbanas, e os valores variam em torno de 55\% para os países em desenvolvimento e com baixa renda, e em média, 85\% para os países desenvolvidos com renda mais alta (WEISS, 2005).

No caso dos países em desenvolvimento, onde as áreas urbanas representam uma média de $55 \%$ da renda nacional, a parcela da população urbana configura apenas 32\%. Enquanto que países desenvolvidos e com alta renda, contribuem em média com $85 \%$ da renda nacional, sendo que a proporção da população urbana é de 79\%. Segundo Weiss (2005), esses valores mostram que quanto maior o nível de urbanização em um país, maior é o seu nível de prosperidade e, inversamente, quanto mais próspero é um país, maior sua urbanização.

Os fatores que contribuem para essas disparidades são vários e, de certo modo, as regiões urbanas são locais que combinam elementos muito importantes para a geração de produtividade e inovação, os quais potencializam as economias locais criarem valor e se tornarem competitivas no mercado global. Entre os fatores importantes estão a especialização e a diversificação dentro do contexto urbano. Somente a região urbana seria capaz de reunir pessoas com habilidades altamente especializadas e avançadas capazes de fomentar o potencial produtivo local. Nesse sentido, a área urbana também é capaz de agregar uma ampla diversidade de pessoas com diferentes conhecimentos e habilidades, tornando essas áreas mais produtivas e mais inovadoras no desenvolvimento e comercialização de novos produtos e novos processos de produção. A combinação entre os fatores que promovem a especialização e a diversificação tornaram-se importantes em todas as áreas urbanizadas e desenvolvidas.

Entretanto, surgem diversas teorias que investigam quais os limites de uma extensiva e dinâmica urbanização das grandes metrópoles, isto é, quais os riscos de um crescimento desordenado e, que podem gerar efeitos adversos ao meio urbano, principalmente em países menos desenvolvidos. Martine et al. (2012) advertem para o acentuado crescimento econômico e a mudança nos padrões de consumo da população menos favorecida. Segundo os autores, a lógica da dinâmica econômica (re)criada no contexto atual, permite o aumento do consumo das populações mais pobres. Entretanto, o incentivo ao consumo ocorre apenas no âmbito de um crescimento econômico generalizado, em que se observam aumentos de renda e de consumo em todas as classes sociais.

A relação entre o crescimento econômico e o acelerado consumismo verificado nas grandes cidades aumentam as diversas e desiguais caracterizações socioespaciais que existem dentro do 
contexto histórico da urbanização brasileira. Em geral, o que pode ser observado ao longo do tempo, e na maioria dos estados brasileiros, seria a configuração de diferentes espaços urbanos, o que equivale a dizer que a urbanização deixa de ser limitada apenas nas cidades, alastrando-se para as periferias e também ao campo.

O processo de transformação da urbanização brasileira é complexo devido, principalmente às suas dimensões continentais e grandes níveis de desigualdades regionais verificados. Alguns reflexos dessas diferenças ratifica a crescente interligação entre as esferas urbana e rural, principalmente via fluxos econômicos e de pessoas, o que facilitaria a articulação entre os dois espaços. No entanto, são os fluxos de pessoas, bens e serviços que constituem o elemento principal na conexão e constituição dos espaços diferenciados (QUEIROZ e BARBIERI, 2012).

No contexto ambiental, a geração de um espaço urbano no Brasil é definida pela fragmentação e invisibilidade de elementos característicos da urbanização, são eles: cursos d'aguas urbanos poluídos; morros, locais de riscos ocupados inadequadamente por ricos e pobres, pavimentações e obras construídas em áreas de proteção ambiental (COSTA, 2012). Além disso, no Brasil, políticas direcionadas à promoção da sustentabilidade ambiental em uma perspectiva urbana integrada são incipientes (QUEIROZ e BARBIERI, 2012). O que deve ser levado em consideração dentro desse contexto seria a urgência e (re)afirmação do papel do Estado frente à vulnerabilidade e a desordenada ocupação territorial nas cidades brasileiras.

Não é difícil apontar as desigualdades e enumerar quão debilitada encontra-se a produção do espaço urbano nos municípios brasileiros mais frágeis economicamente. Nessas localidades, há grande probabilidade de um intenso processo de favelização em suas periferias, carência em áreas prioritárias como saúde, educação, habitação e urbanismo, enfim, elementos essenciais antes de uma discussão ambiental mais aprofundada. O planejamento ambiental, nesse contexto, promove e incentiva a discussão de um conjunto de fatores importantes tanto ao planejamento urbano quanto ao intervencionismo do Estado.

Por fim, o que deve ser levado em consideração acerca das questões sobre a urbanização e seus efeitos sob a ótica ambiental seria um maior planejamento em áreas cuja abrangência possui escala metropolitanas e uma grande difusão de mecanismos que possibilitem a articulação das dimensões sociais, políticas e urbanas (COSTA, 2012). A sustentabilidade de longo prazo requer mudanças radicais de atitudes, comportamentos e principalmente de políticas. Tais transformações, de certo modo, são difíceis de serem adotadas diante de um conceito de desenvolvimento, a priori, eficaz no incentivo à uma cultura consumista (MARTINE et al., 2012). 
A seguir, será apresentada a metodologia adotada na tentativa de caracterizar os estados brasileiros, mediante as variáveis selecionadas, de acordo com as dimensões socioeconômicas, ambientais e demográficas.

\section{ABORDAGEM METODOLÓGICA}

\subsection{O método de análise de componentes principais (ACP)}

A análise dos componentes principais é um método bastante utilizado para reduzir a dimensionalidade dos dados multivariados. A técnica permite expressar as informações disponíveis em poucas variáveis (componentes). Deste modo, a redução no número de variáveis fará com que a análise e a visualização dos dados sejam mais simplificadas. Entretanto, o método de ACP exige uma escolha entre a simplicidade, com um pequeno número de dimensões (variáveis) e a integralidade, isto é, mais dimensões que possam captar uma maior quantidade de informações.

O principal objetivo da análise de componentes principais é fazer um agrupamento de $\mathrm{X}_{1}, \ldots$, $\mathrm{X}_{\mathrm{i}}$ variáveis e criar índices $\mathrm{Z}_{1}, \ldots, \mathrm{Z}_{\mathrm{i}}$ que sejam não correlacionados na ordem de sua importância e que expliquem a variação dos dados (MANLY, 2008). Portanto, a escolha do método tem por objetivo sintetizar a variabilidade das informações referente aos estados.

$\mathrm{O}$ primeiro componente principal, representado por $\mathrm{Z}_{1}$, é a combinação linear das variáveis $\mathrm{X}=\left[\mathrm{X}_{1}, \ldots, \mathrm{X}_{\mathrm{i}}\right]$ com a maior variância possível. $\mathrm{O}$ segundo componente $\mathrm{Z}_{2}$, é dado pela combinação linear de $\mathrm{X}$ que explica a maioria das informações não captadas por $\mathrm{Z}_{1}$.

Ressalta-se que a técnica da ACP buscar maximizar a variância, que pode ser altamente sensível às diferenças de escala entre variáveis. Sendo assim, é comum fazer a padronização dos dados cuja obtenção ocorre através de uma decomposição de autovalor da matriz de correlação. Cada autovetor, indicado por $\mathrm{u}$, representa a direção de um desses eixos principais. $\mathrm{O}$ vetor $\mathrm{u}$ controla os pesos usados para formar a combinação linear de Xs, que resulta nos pontos do componente principal, sendo representado da seguinte forma:

$$
\mathrm{Z}_{\mathrm{i}}=\mathrm{Xs.u}
$$

Cada autovalor, representado por $\lambda$, é igual à variância do componente principal $\mathrm{Z}_{\mathrm{i}}$. A matriz de covariância para os componentes principais, representada por D, é uma matriz diagonal com $\left(\lambda_{1}, \ldots \lambda_{\mathrm{i}}\right.$.) na diagonal (CALAZANS et al., 2012). A soma das variâncias de todos os componentes principais é igual a p, que é o número das variáveis na matriz X. Portanto, a proporção da variação explicada pelos primeiros componentes principais é dada por:

$$
\sum_{i=1}^{c} \frac{\lambda_{i}}{p}
$$


De acordo com a interpretação dos componentes principais é válido observar as cargas desses componentes, que são definidas como sendo as correlações entre as variáveis originais X e os componentes principais Z. A matriz das cargas, representada por F, pode ser calculada como:

$\mathrm{F}=\mathrm{UD}^{1 / 2}$

onde $\mathrm{U}$ representa a matriz dos autovetores e D a matriz de covariância dos componentes principais.

\subsection{O método de análise de cluster}

O reconhecimento de clusters é por natureza uma análise exploratória que visa avaliar grupos similares dentro de uma amostra maior. Logo, pela análise é possível sintetizar o número de informações, observar os objetos (no caso os estados) similares em categorias iguais a partir de $\mathrm{k}$ variáveis associadas (MANLY, 2008). Além disso, existe uma classificação do tipo qualitativa e uma quantitativa. O tipo de classificação que será utilizada no presente trabalho é quantitativa e a metodologia adotada para fazer esse agrupamento será baseada na análise de cluster.

A análise de cluster é um agrupamento constituído de acordo com as similaridades ou dissimilaridades dos objetos. A maneira de mensurar as similaridades é o cálculo da distância de cada objeto a todos os outros objetos. A distância pode ser medida de acordo com as variáveis escolhidas para descrever os objetos. Há várias formas de classificar os grupos segundo diferentes cálculos de distância e cada cálculo formará agrupamentos distintos.

A seguir, será descrito a síntese dos métodos de análise, entre eles a técnica de agrupamento não hierárquica utilizada na configuração dos clusters apresentados no trabalho.

\subsubsection{Síntese dos métodos de análise de clusters}

Para identificar a tendência da caracterização dos Estados, foi utilizada a análise de cluster (agrupamentos), e o método adotado foi o das k-médias, também chamado de k-means cluster. Os métodos de análise de cluster são subdivididos em uma abordagem hierárquica e uma de partição. Os métodos não hierárquicos são técnicas que têm como finalidade encontrar uma partição de $n$ elementos em $\mathrm{k}$ grupos (clusters), de modo que a partição obedeça dois critérios: coesão interna (semelhança) e isolamento (separação) dos clusters formados. A partir daí, buscando-se a melhor partição de ordem k, algum critério de qualidade da partição deve ser implementado. Em geral, não é possível criar todas as partições possíveis de ordem $\mathrm{k}$, sendo necessários processos que verifiquem partições quase ótimas (MINGOTI, 2005). 
Vale ressaltar que as técnicas de agrupamento não hierárquicas se diferenciam das hierárquicas em diferentes pontos. Em primeiro lugar, necessitam que o pesquisador tenha especificado o número de clusters $\mathrm{k}$ desejado, sendo o oposto das técnicas hierárquicas aglomerativas. Ademais, em cada etapa do agrupamento, os novos grupos podem ser formados por intermédio da divisão ou junção de grupos já combinados em passos anteriores. $\mathrm{Na}$ verdade, isto equivale a dizer que, caso em alguma etapa do algoritmo dois elementos tiverem sido agrupados, não será indispensável que eles estejam juntos na partição final (MINGOTI, 2005).

Deste modo, o método $k$-means é baseado em agrupamentos não hierárquico por repartição, e consiste de um procedimento onde, dado um número de clusters previamente determinado, calcula pontos que representam os "centros" destes clusters e que são espalhados homogeneamente. Em outras palavras, o procedimento inicia-se usando os valores dos primeiros k casos como estimativas temporárias das médias dos agrupamentos. Os centróides iniciais são formados através da designação de cada caso ao cluster de centro mais próximo. Com a inclusão de cada caso, a média altera-se, alterando assim o centróide. Um processo iterativo é usado para achar os centróides finais de cada cluster.

A cada passo, os casos são agrupados ao cluster de centro mais próximo, e novamente as médias são recalculadas. Este processo continua até que não haja mais alterações nas médias ou que um número pré-determinado de iterações aconteça, encerrando-se o processo.

\section{BASE DE DADOS}

A base de informações para o estudo sobre os estados brasileiros (Tabela 1), incluindo o Distrito Federal, corresponde ao relatório disponível sobre Indicadores de Desenvolvimento Sustentável (IDS, 2010), divulgados pelo Instituto Brasileiro de Geografia e Estatística (IBGE). O relatório apresenta um conjunto de informações e agrega diferentes fontes de dados como: a Pesquisa Nacional por Amostra de Domicílios (PNAD); o Departamento de Informática do Sistema Único de Saúde (DATASUS); a Pesquisa Nacional de Saneamento Básico (PNSB); o Instituto Nacional de Pesquisas Espaciais (INPE) e a Pesquisa Agrícola Municipal (PAM).

As proxies estaduais foram elaboradas para três distintas dimensões, a saber: variáveis socioeconômicas, demográficas e ambientais. De acordo com as variáveis utilizadas para capturar a dimensão socioeconômica, buscou-se verificar o reflexo da infraestrutura urbana e sanitária em todo o país. As variáveis propostas nessa dimensão são as seguintes: produto interno bruto (PIB) per capita, média dos anos de estudo, internações hospitalares em decorrência do inadequado saneamento ambiental, rendimento médio mensal real, taxa de fecundidade, proporção dos estabelecimentos de saúde por indivíduo e a taxa de urbanização. 
Nesse trabalho, as variáveis foram utilizadas na sua forma real, isto é, não foram deflacionadas, de modo que o PIB per capita e o rendimento médio mensal real foram utilizados como medidas da atividade econômica dos estados. O rendimento médio do trabalho principal é usado para mensurar o efeito da riqueza dos indivíduos sobre as demais dimensões.

Em relação à dimensão demográfica, a taxa média geométrica de crescimento anual da população residente é uma proxy dessa dimensão, uma vez que quanto maior for a velocidade de crescimento da população, maior é a possibilidade de trocas, externalidades, acesso a bens e serviços. A análise desta variável também nos permitirá identificar se o conjunto de Estados que possuem a maior (menor) velocidade de crescimento da população são aqueles que também possuem maiores (menores) condições de urbanização e ambientais.

Para compor a dimensão ambiental dos estados as seguintes variáveis foram eleitas: a proporção de municípios, dentro de cada região, com conselho ambiental ativo; a proporção de quantidade de lixo recolhido; distribuição percentual de moradores com esgotamento; proporção de desmatamento no estado e a quantidade de fertilizantes fornecidas ao consumidor final. Os indicadores descritos anteriormente levam em consideração o esforço (ou a displicência) do Estado em relação à utilização e a destinação dos recursos públicos para conservação e preservação do meio ambiente. Como exemplo, podem ser citadas as variáveis ligadas ao desmatamento e a proporção de fertilizantes entregue ao consumidor final. Ambas as proxies contribuem para o aumento na emissão de gases de efeito estufa para a atmosfera e, particularmente o fertilizante, associa-se com eutrofização dos rios e lagos, e com a acidificação dos solos, à contaminação de aquíferos e reservatórios de água, à geração de gases associados ao efeito estufa e à destruição da camada de ozônio (IDS, 2010).

A temática ambiental é recente e, por isso, não contam com uma grande tradição de produção estatística. Deste modo, há uma pequena disponibilidade de informações para a construção dos indicadores requeridos para uma descrição mais completa (IDS, 2010). Algumas lacunas importantes podem ser observadas na escolha das variáveis entre as quais destacam-se o uso da água, a erosão e a perda do solo.

Tabela 1 - Descrição das variáveis para os Estados brasileiros 


\begin{tabular}{|c|c|c|}
\hline Dimensão Socioeconômica & Fonte & Ano \\
\hline Produto interno bruto per capita & IBGE & 2008 \\
\hline $\begin{array}{l}\text { Média de anos de estudo das pessoas de } 25 \text { anos ou mais } \\
\text { de idade }\end{array}$ & IBGE/PNAD & 2009 \\
\hline $\begin{array}{l}\text { Proporção de internações hospitalares por doenças } \\
\text { relacionadas ao saneamento ambiental inadequado }\end{array}$ & $\begin{array}{l}\text { Ministério da Saúde } \\
\text { (DATASUS) }\end{array}$ & 2010 \\
\hline $\begin{array}{l}\text { Rendimento médio mensal real das pessoas de } 10 \text { anos ou } \\
\text { mais de idade, com rendimento }\end{array}$ & IBGE/PNAD & 2009 \\
\hline Taxa de fecundidade & IBGE & 2009 \\
\hline Proporção de estabelecimentos de saúde & IBGE & 2010 \\
\hline Taxa de urbanização & IBGE & 2010 \\
\hline Dimens ão Demográfica & Fonte & Ano \\
\hline $\begin{array}{l}\text { Taxa média geométrica de crescimento anual da população } \\
\text { residente }\end{array}$ & IBGE & 2010 \\
\hline Dimensão Ambiental & Fonte & Ano \\
\hline $\begin{array}{l}\text { Proporção de municípios com cons elho de meio ambiente } \\
\text { ativo }\end{array}$ & IBGE & 2009 \\
\hline Proporção da quantidade de lixo coletado & IBGE /PNSB & 2008 \\
\hline $\begin{array}{l}\text { Distribuição percentual de moradores em domicílios } \\
\text { particulares permanentes que possuem esgotamento por }\end{array}$ & IBGE/PNSB & 2008 \\
\hline Proporção de desmatamento & INPE & 2009 \\
\hline $\begin{array}{l}\text { Proporção da quantidade de fertilizantes entregue ao } \\
\text { consumidor final }\end{array}$ & IBGE/PAM & 2009 \\
\hline
\end{tabular}

Fonte: Elaboração própria com base nos dados do IBGE

Pretende-se, com a utilização das variáveis descritas acima, à luz da economia regional, caracterizar e especificar os determinantes dos estados de maior e menor densidade urbana que compõe as dimensões socioeconômicas, demográficas e ambientais. A aplicação da análise de componentes principais (ACP) sobre o conjunto de indicadores possibilitará extrair de forma condensada as características dos indicadores estaduais e, posteriormente, será possível visualizar os resultados na análise de cluster. Na verdade, o objetivo da tipologia proposta é gerar uma base de componentes relativamente homogêneos quanto a um conjunto de variáveis que poderiam caracterizar os estados brasileiros, a partir das variáveis em análise. É importante ressaltar que o método ACP fornece um número de componentes principais igual ao número de variáveis originais, todavia é interessante considerar um número mínimo de componentes os quais contenham a maior parte da variabilidade do vetor aleatório.

\section{ANÁlise dOS RESUltados PARA A ANÁlise DE COMPONENTES PRINCIPAIS (ACP) E PARA A ANÁLISE DE CLUSTERS}


A análise de componentes principais viabiliza a extração de informações de maneira condensada referente às características dos vinte e sete estados brasileiros, considerando-se as treze variáveis originais (vetor aleatório). O Quadro 1 mostra os resultados da ACP baseados nas percentagens da variância interligada a cada uma das variáveis, sendo o primeiro componente representado por $36.18 \%$ da variabilidade dos dados.

Quadro 1- Proporção da variância explicada através da Análise de Componentes Principais $(\mathrm{ACP})$

\begin{tabular}{|l|c|c|}
\hline \multirow{2}{*}{ Componentes } & \multicolumn{2}{|c|}{ Variância explicada (\%) } \\
\cline { 2 - 3 } & Individual & Acumulada \\
\hline Componente 1 & 36.18 & 36.18 \\
Componente 2 & 18.58 & 54.76 \\
Componente 3 & $\mathbf{1 2 . 5 4}$ & $\mathbf{6 7 . 3 0}$ \\
Componente 4 & 9.44 & 76.73 \\
Componente 5 & 7.91 & 84.64 \\
Componente 6 & 5.30 & 89.94 \\
Componente 7 & 3.58 & 93.53 \\
Componente 8 & 2.37 & 95.90 \\
Componente 9 & 1.50 & 97.40 \\
Componente 10 & 1.37 & 98.76 \\
Componente 11 & 0.72 & 99.48 \\
Componente 12 & 0.33 & 99.81 \\
Componente 13 & 0.19 & 100.00 \\
\hline
\end{tabular}

Fonte: Elaboração própria com base no programa Stata 10.

No segundo componente, a variabilidade do vetor aleatório respondeu por $18.58 \%$, e também representa um forte peso na representação das variáveis. Em seguida, o terceiro componente representa apenas $12.54 \%$ da variância dos dados. É oportuno ressaltar que a técnica é utilizada quando a preocupação principal é o número mínimo de novas variáveis (componentes) importantes para representar uma grande parcela da variância total das variáveis originais. Como princípio básico, seleciona-se um número mínimo de componentes que atinja $70 \%$ da variância total da amostra. Logo, de acordo com os resultados da análise de componentes principais, houve a preferência pela seleção dos três principais componentes de maior peso (JOHNSON e WICHERN,2002). Levando-se em consideração o grande peso dos três primeiros componentes, os quais respondem por $67.30 \%$ da variabilidade do conjunto das informações, serão discutidos a 
seguir, os resultados observados pelos três primeiros componentes, ao contrário da variação encontrada dos demais autovalores, inferior a $10 \%$.

De acordo com os resultados do Quadro 2 observa-se que o componente 1, denominado de áreas urbanas em expansão, apresenta regiões com características de cidades metropolitanas e sinais condizentes de acordo com a teoria nas variáveis representativas de PIB per capita, baixa proporção de internações hospitalares relacionadas ao saneamento inadequado, população escolarizada, taxa de fecundidade negativa e elevada taxa de urbanização. Os resultados, evidenciados em negrito, revelam estados propícios à construção de um espaço urbano e que visam interrelações entre população, meio ambiente e infraestrutura urbana. É importante ressaltar que essas relações são dinâmicas e complexas, no entanto, o efetivo planejamento dos estados brasileiros dependerá de um desenvolvimento sustentável de cada uma das diferentes dimensões, isto é, social, ambiental e econômica.

Quadro 2- Coordenadas das variáveis nos três primeiros eixos dos componentes principais

\begin{tabular}{|c|c|c|c|}
\hline \multirow[b]{2}{*}{ Variáveis } & \multicolumn{3}{|c|}{ COMPONENTES } \\
\hline & $\begin{array}{l}1 \text { (áreas urbanas } \\
\text { em expansão) }\end{array}$ & $\begin{array}{c}2 \text { (áreas com pouca } \\
\text { infraes trutura, elevado } \\
\text { des matamento e cres cimento } \\
\text { populacional) } \\
\end{array}$ & $\begin{array}{c}3 \text { (áreas estagnadas } \\
\text { e de baixo } \\
\text { crescimento } \\
\text { econômico) }\end{array}$ \\
\hline Produto interno bruto per capita & 0.4378 & 0.0285 & -0.0287 \\
\hline $\begin{array}{l}\text { Média de anos de estudo das pessoas de } 25 \text { anos ou mais de } \\
\text { idade }\end{array}$ & 0.4160 & 0.1962 & -0.0395 \\
\hline $\begin{array}{l}\text { Proporção de internações hospitalares por doenças } \\
\text { relacionadas ao saneamento ambiental inadequado }\end{array}$ & -0.0091 & -0.1608 & -0.0268 \\
\hline $\begin{array}{l}\text { Rendimento médio mensal real das pessoas de } 10 \text { anos ou mais } \\
\text { de idade }\end{array}$ & 0.4310 & 0.0947 & -0.0684 \\
\hline Taxa de fecundidade & -0.2324 & 0.3904 & -0.3627 \\
\hline Proporção de estabelecimentos de saúde & 0.0422 & 0.3149 & 0.5264 \\
\hline Taxa de urbanização & 0.4071 & -0.0388 & -0.0662 \\
\hline $\begin{array}{l}\text { Taxa média geométrica de crescimento anual da população } \\
\text { residente }\end{array}$ & 0.0325 & 0.5708 & -0.0836 \\
\hline Proporção de municípios com conselho de meio ambiente ativo & 0.3617 & 0.1136 & -0.1805 \\
\hline Proporção da quantidade de lixo coletado & -0.0155 & -0.1091 & 0.5611 \\
\hline $\begin{array}{l}\text { Distribuição percentual de moradores em domicílios } \\
\text { particulares permanentes que possuem esgotamento por rede }\end{array}$ & 0.3034 & -0.3330 & 0.2168 \\
\hline Proporção de desmatamento & -0.0146 & 0.4564 & 0.4153 \\
\hline $\begin{array}{l}\text { Proporção da quantidade de fertilizantes entregue ao } \\
\text { consumidor final }\end{array}$ & 0.0601 & 0.0540 & -0.0723 \\
\hline
\end{tabular}

Fonte: Elaboração própria com base no programa Stata 10.

Já o segundo componente, chamado de áreas com pouca infraestrutura, elevado desmatamento e crescimento populacional, provavelmente representa regiões com recursos mais escassos, principalmente pela baixa taxa de urbanização, contudo possuem um rendimento mensal positivo e um bom nível de escolaridade da população. As variáveis que reforçam esse resultado, destacadas no Quadro 2 em negrito, estão relacionadas à dimensão econômica, pois observou um pequeno PIB per capita e uma elevada taxa de fecundidade. Além disso, a respeito da dimensão 
demográfica há um valor bastante elevado e, quanto a dimensão ambiental, há indícios de que na região o planejamento ambiental não seja adequado, em virtude, principalmente, dos resultados verificados nas variáveis de distribuição percentual da população com esgotamento e na elevada proporção de focos de desmatamento. Tais resultados evidenciam bastante as conhecidas desigualdades socioespaciais típicas da urbanização brasileira, consolidadas em diferentes patamares de vulnerabilidade sob a ótica ambiental. (COSTA, 2012).

O último componente a ser analisado, denominado de áreas estagnadas e de baixo crescimento econômico, corresponde a $12.54 \%$ da variabilidade dos dados, fornecendo a caracterização de regiões com baixo PIB per capita. Observa-se que a baixa taxa de urbanização é acompanhada de uma população menos escolarizada e com rendimento médio mensal negativo, o que pode indicar um nível de desemprego elevado nessas localidades. Entretanto, o crescimento populacional é negativo, assim como a taxa de fecundidade, e a proporção de internações hospitalares é baixa. Em relação à dimensão ambiental, há nessas regiões considerável proporção de desmatamento, grande quantidade de lixo coletado e baixa participação de conselhos ambientais ativos. Entretanto, os moradores possuem acesso à rede de esgotamento, e também, foi o único entre os demais componentes com baixa quantidade de fertilizantes entregue ao consumidor final.

Os resultados dos componentes podem ser explicados de acordo com a caracterização de uma expansão periférica, isto é, há uma concentração de pobreza nesses locais, e que podem estar associados a um nível de segregação urbana (entre ricos e pobres). Torres e Sydenstricker-Neto (2012) explicam que a chamada periferia no Brasil é uma marca característica em todo o território. Os autores argumentam o fato de que no País esse espaço está localizado em lugares absorvidos pelo veloz crescimento urbano nas grandes cidades e, podem ser identificados por três distintos fenômenos: rápido crescimento demográfico, presença de moradia informal e elevada concentração de pobreza. Apesar da caracterização do componente 3 não apresentar um elevado crescimento demográfico, há indícios de que nessas regiões tenham ocorrido transições demográficas e urbanas. Essa transição é marcada pela passagem de uma etapa de alta fecundidade e mortalidade para outro em que ambas são consideradas baixas (TORRES e SYDENSTRICKER-NETO, 2012).

Ademais, os resultados apresentados pela análise de componentes principais não apontam um direcionamento exato em relação ao crescimento populacional e às condições ambientais e de urbanização nos estados. Em outras palavras, há uma grande disparidade entre os resultados verificados entre os componentes, com exceção do componente 1, em que se observou uma taxa de crescimento populacional positiva e condições ambientais e sanitárias favoráveis (baixo desmatamento e grande parte dos domicílios com rede coletora de esgoto). 
Após a análise de componentes principais foi realizada a técnica de análise de clusters (Quadro 3). A metodologia de identificação de clusters possibilitará visualizar os efeitos da combinação entre as variáveis selecionadas, e assim, permitirá a identificação dos Estados brasileiros de maior (menor) relação entre as diferentes dimensões propostas no trabalho, que foram caracterizados em seis clusters.

Quadro 3- Caracterização dos clusters em relação às variáveis analisadas

\begin{tabular}{|l|c|c|c|c|c|c|}
\hline \multicolumn{1}{|c|}{ Variáveis analisadas } & Cluster 1 & Cluster 2 & Cluster 3 & Cluster 4 & Cluster 5 & Cluster 6 \\
\hline Produto interno bruto per capita & 21669 & 7146 & 10792 & 17744 & 13828 & 45978 \\
Média de anos de estudo das pessoas de 25 anos ou mais de idade & 7.8750 & 5.7555 & 7.0167 & 7.3333 & 7.0500 & 9.6000 \\
Proporção de internações hospitalares por doenças relacionadas ao saneamento & 5.9000 & 6.7222 & 2.6000 & 2.9000 & 4.8250 & 2.8000 \\
ambiental inadequado & & & & & & \\
Rendimento médio mensal real das pessoas de 10 anos ou mais de idade, com & 1288.8 & 725.5 & 979.2 & 1174.3 & 1029.8 & 2339 \\
rendimento & 1.8425 & 2.1777 & 2.4650 & 1.9933 & 1.9275 & 1.8400 \\
Taxa de fecundidade & 0.0005 & 0.0005 & 0.0006 & 0.0006 & 0.0005 & 0.0007 \\
Proporção de estabelecimentos de saúde & 90.4675 & 72.3856 & 77.3950 & 84.1033 & 84.1033 & 96.6200 \\
Taxa de urbanização & 1.2425 & 1.1989 & 2.3517 & 1.1067 & 1.6425 & 2.2800 \\
Taxa média geométrica de crescimento anual da população residente & 38.1500 & 18.3333 & 27.6333 & 43.7000 & 33.9750 & 100.00 \\
Proporção de municípios com conselho de meio ambiente ativo & 0.0017 & 0.0012 & 0.0016 & 0.0008 & 0.0011 & 0.0009 \\
Proporção da quantidade de lixo coletado & 65.8500 & 27.4111 & 19.0833 & 32.7000 & 42.4500 & 89.4000 \\
Distribuição percentual de moradores em domicílios particulares permanentes que \\
possuem esgotamento por rede coletora & 0.0001 & 0.0004 & 0.0151 & 0.0013 & 0.0007 & 0.0000 \\
Proporção de desmatamento & 0.0279 & 0.0146 & 0.0160 & 0.2312 & 0.0900 & 0.0059 \\
Proporção da quantidade de fertilizantes entregue ao consumidor final & &
\end{tabular}

Fonte: Elaboração própria com base no programa Stata 10.

Com base na dimensão socioeconômica (Quadro 3), observa-se que os clusters se diferenciam bastante em determinadas variáveis. O cluster 6, representado pelo Distrito Federal (Figura 1), é o cluster que apresenta maiores proporções de PIB per capita, além da média de anos de estudo da população e do rendimento em relação aos demais agrupamentos. No cluster 1, que agrega os estados do Espírito Santo, Rio de Janeiro, Santa Catarina e São Paulo, observa-se uma elevada taxa de urbanização, em média $90.47 \%$ e, elevado rendimento médio mensal seguido pelo PIB per capita. No entanto, apesar do bom desempenho dos indicadores econômicos, a proporção de internações hospitalares por doenças relacionadas ao saneamento inadequado foi a segunda maior entre os demais clusters. É importante ressaltar que todos os estados do cluster 1 possuem uma dinâmica urbana bastante peculiar e esse resultado evidencia os contrastes e a heterogeneidade presente dentro do seu respectivo processo de urbanização.

No cluster 4, representado pelos estados de Mato Grosso, Paraná e Rio Grande do Sul, e o cluster 5, composto por Amazonas, Goiás, Mato Grosso do Sul e Minas Gerais apresentaram níveis dos indicadores socioeconômicos que se diferenciam apenas nos valores em relação ao PIB per capita e proporção de internações hospitalares. Além disso, no cluster 2, que abrange os estados de 
Alagoas, Bahia, Ceará, Maranhão, Pará, Paraíba, Pernambuco, Piauí, e no cluster 3 que agrega os estados do Acre, Amapá, Rondônia, Roraima, Sergipe e Tocantins, observou-se os menores valores para os indicadores econômico, educacional e consideráveis proporções para a taxa de fecundidade e proporção para internações relacionadas ao saneamento inadequado. A Figura 1 apresenta o mapa de clusters segundo a caracterização das variáveis selecionadas

Figura 1 - Mapa de clusters dos Estados brasileiros
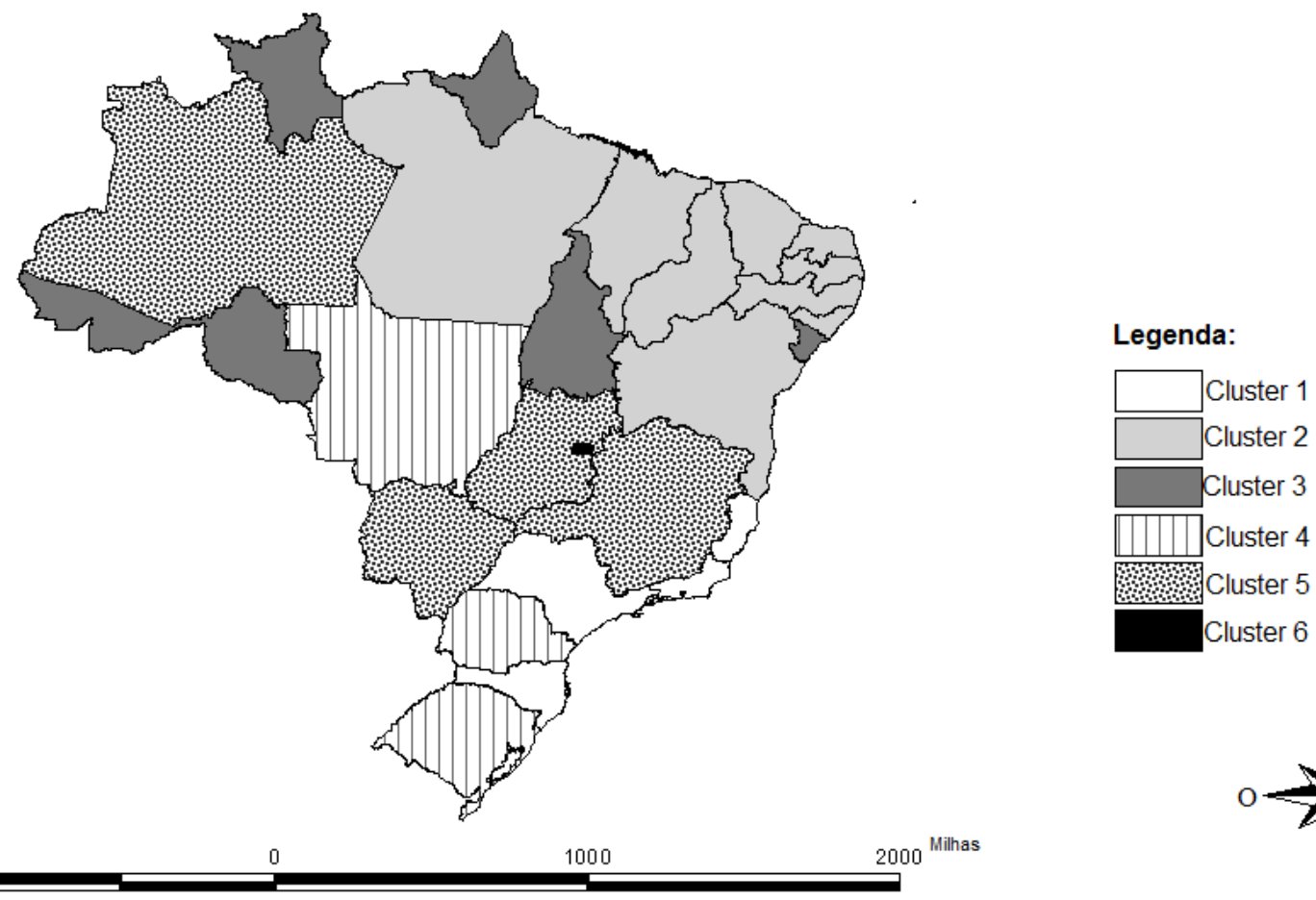

Fonte: Elaboração própria com base no programa ArcView 3.0

Sob a ótica da dimensão demográfica, observa-se que a taxa foi superior a $2 \%$ em dois clusters (3 e 6). Tal resultado pode indicar um aumento na densidade populacional que possivelmente, a médio e longo prazo pode gerar alguns problemas de crescimento desordenado da população, que sem qualquer planejamento, pode provocar o surgimento de novas periferias. As consequências para a criação desses espaços urbanos vêm acompanhadas de habitações irregulares, uso irregular do solo, precária infraestrutura e, principalmente, da degradação ambiental.

Por fim, o cluster que obteve os melhores indicadores na dimensão ambiental foi o que pertence à capital, Distrito Federal, com participação ativa em conselho de meio ambiente, baixa proporção de fertilizantes inclusas nos produtos entregues ao consumidor final, grande cobertura de esgotamento por rede coletora e sem focos de desmatamento. Em seguida, os clusters 1, 4 e 5 
exibiram bons indicadores a respeito da proporção de regiões com conselho de meio ambiente ativo e distribuição de domicílios com esgotamento sanitário.

No entanto, os clusters 2 e 3 que representam basicamente as regiões Norte e Nordeste, obtiveram resultados inferiores aos registrados nos demais clusters. Os baixos valores de proporções de estados com conselhos ambientais e a baixa cobertura de domicílios com rede de esgoto contribuem para esse resultado, evidenciando o baixo acesso a serviços básicos de infraestrutura (água e esgoto).

Para auxiliar na caracterização extraída nos resultados do método de ACP e na análise de clusters foi realizado o procedimento de agrupamento hierárquico aglomerativo. De modo semelhante ao método ACP, a análise hierárquica considera as treze variáveis selecionadas e revela como os Estados brasileiros podem ser agrupados pelas influências de suas similaridades. Como pode ser visualizado na Figura 2, três grandes grupos estão destacados, um apenas com o Distrito Federal, e os demais com Estados de diversas regiões brasileiras. O grupo onde está concentrado, basicamente, as regiões Sul e Sudeste, com exceção do Estado de Mato Grosso, foi subdivido em dois subgrupos e apresentam características próximas, que representam os clusters 1 e 4 .

De acordo com o terceiro grupo, o maior entre eles, observa-se que há uma combinação de fatores diversos entre si. Os clusters 2, 3 e 5, descritos anteriormente, estão agregados nesse grande grupo. O que se pode inferir da análise do cluster hierárquico é que existem grandes evidências das disparidades regionais encontradas no Brasil, principalmente, das três dimensões descritas no presente trabalho (socioeconômica, demográfica e ambiental). Outra observação importante verificada nos resultados seria em relação ao atendimento das necessidades básicas de infraestrutura (esgotamento, desmatamento, coleta de lixo, conselhos ambientais municipais) associados aos estados detentores de maior renda média mensal, PIB per capita e elevada escolarização da população.

Figura 2 - Cluster hierárquico para os Estados brasileiros 


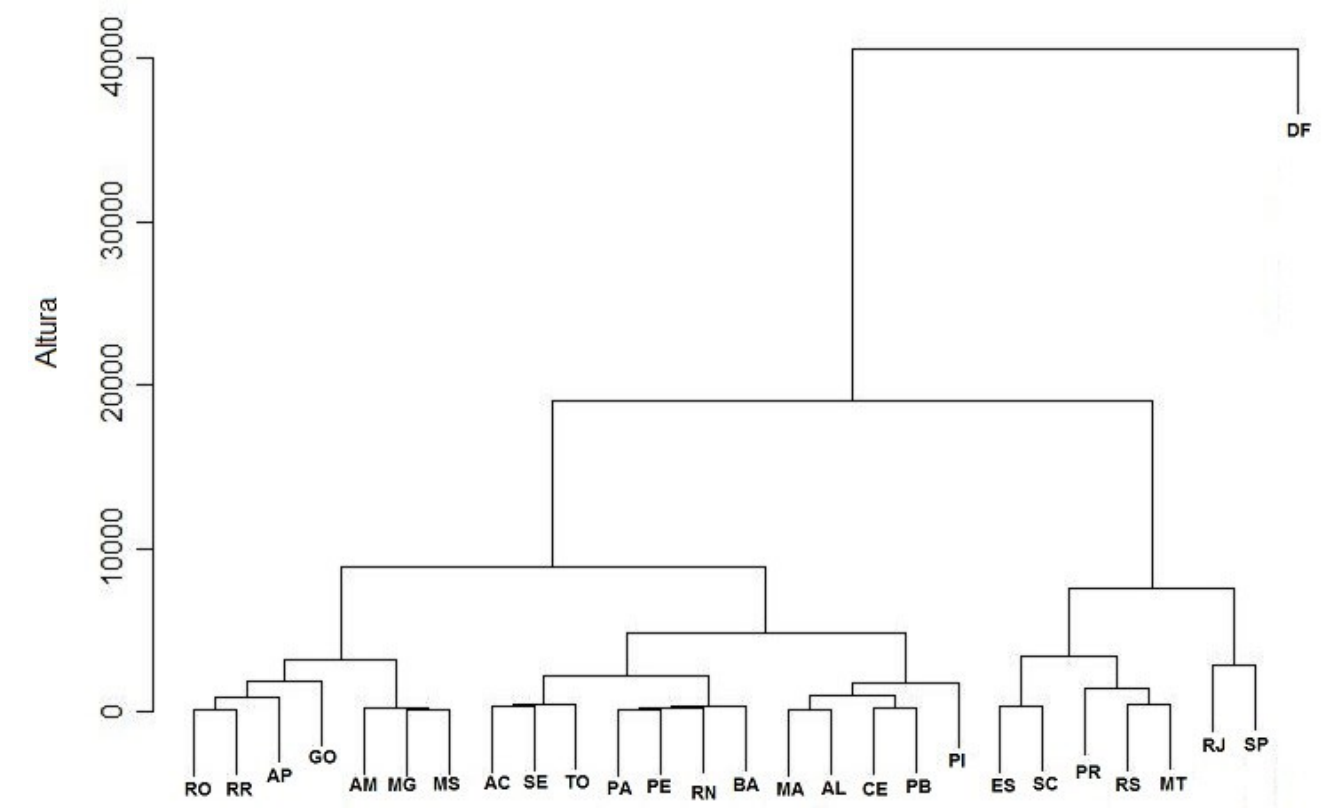

Fonte: Elaboração própria com base no programa SPlus.

Deste modo, as técnicas que permitiram a análise de cluster confirmam os resultados observados na ACP, de maneira que possibilitam a identificação de diversos grupos formados pelos estados brasileiros, a partir das variáveis selecionadas.

\section{CONSIDERAÇÕES FINAIS}

O objetivo deste trabalho foi compreender a relação dos estados brasileiros a respeito da dinâmica urbana e ambiental. No cenário apresentado, a discussão entre questões socioeconômicas e relacionadas aos temas ambientais não esgotam os estudos na área e, além disso, permite que o debate seja promovido de maneira atual e com a devida emergência. Sabe-se que as desigualdades econômicas e sociais particulares à urbanização brasileira são estabelecidas em diferentes níveis, sendo de relevante importância estudos que permitem identificar e, até mesmo, avaliar as relações intrínsecas dessas desigualdades com a temática ambiental.

A aplicação metodológica utilizada no artigo, referente à análise de componentes principais e à análise de cluster, permitiu uma observação atual, isto é, uma tipologia de como os estados brasileiros desempenham suas ações em diferentes dimensões relacionadas aos aspectos socioeconômicos, demográficos e ambientais. Os resultados apontaram para a caracterização de regiões bem distintas e que apresentaram características peculiares aos espaços urbanos de maior, média e baixa infraestrutura (periferias), possuindo também relações diversas entre os aspectos ambientais. 
A partir desses resultados, observou-se que algumas regiões se destacaram em maior intensidade nas dimensões socioeconômica, demográfica e ambientais, como por exemplo, Distrito Federal que apresentou proporções superiores em relação às demais unidades geográficas. Nos estados do Espírito Santo, Rio de Janeiro, Santa Catarina e São Paulo houve um contraste entre os indicadores econômicos e sanitários. Esse resultado pode indicar uma dinâmica urbana bastante peculiar, evidenciando os contrastes e a heterogeneidade presente em cada região.

Por outro lado, os estados de Mato Grosso, Paraná e Rio Grande do Sul, Amazonas, Goiás, Mato Grosso do Sul e Minas Gerais apresentaram níveis socioeconômicos similares, de acordo com as variáveis selecionadas para o estudo. Contudo, observou-se nas regiões Norte e Nordeste menores valores para os indicadores econômico e educacional.

Em termos ambientais, as regiões Sudeste, Sul, Centro-Oeste e o Amazonas tiveram bons indicadores em relação às variáveis selecionadas. No entanto, os estados que representam as regiões Norte e Nordeste obtiveram resultados preocupantes com baixas proporções de localidades com conselhos ambientais e baixo acesso a serviços básicos de infraestrutura (água e esgoto).

Com base nas variáveis selecionadas e a partir dos resultados verificados na aplicação metodológica, confirmou-se a importância de estudos no Brasil relacionados às várias dimensões de desenvolvimento tanto no aspecto urbano quanto aos fatores socioeconômico, demográfico e ambiental. Apesar de alguns avanços recentes, como a oportunidade de debates relevantes à temática ambiental, configurado no Rio +20 , o Brasil ainda precisa enfrentar obstáculos com o objetivo de alcançar um crescimento sustentável nas cidades. Tais alternativas e soluções devem visar, principalmente, o uso consciente dos recursos naturais, a diminuição das desigualdades sociais e regionais e a condução, por parte dos planejadores públicos, de ações que viabilizem o desenvolvimento sustentável a partir do envolvimento de diferentes atores nas esferas governamental e social.

Por fim, no intuito de futuras contribuições à literatura da área, pretende-se avaliar a dimensão do contexto urbano interligada à temática ambiental com um recorte territorial de menor escala, como por exemplo, municípios e regiões metropolitanas. A ideia seria a de captar influências e impactos das grandes mudanças climáticas sobre as dimensões culturais, econômicas, sociais e ambientais nas unidades de análise e suas possíveis consequências.

\section{REFERÊNCIAS BIBLIOGRÁFICAS}

BARRET, S. The coming global climate-technology revolution. Journal of Economic Perspectives. v. 23, n.2, p. 53-75. 2009

BELlEN, H. M. Indicadores de sustentabilidade: uma análise comparativa. Rio de Janeiro: Fundação Getúlio Vargas, 2005. 256p. 
CALAZANS, J. A., MONTENEGRO, R. L. G., LENA, F. F. A heterogeneidade do perfil das mulheres mineiras: uma análise das decisões femininas sob a ótica do trabalho, da educação e da família nos anos de 2000 e 2010. In: Anais do XVIII Encontro Nacional de Estudos Populacionais, 2012.

CARRILLO-HERMOSILlA, J., DEL RIO, P., KONOLLA, T. Diversity of eco-innovations: reflections from selected case studies. Journal of Cleaner Production, v.18, n.10-11, p.

1073-1083, 2010.

CHADCHAN, J., SHANKAR, R. Emerging urban development issues in the context of globalization. Journal of ITPI (Institute of Town Planners India) V. 6, n. 2, p. 78-85, 2009.

COSTA, H. S. M. Planejamento e ambiente em regiões metropolitanas. In: MARTINE, G. (Ed.) OJIMA, R., BARBIERI, A. F., CARMO, R. L. (Co-Orgs.) População e Sustentabilidade na era das mudanças ambientais globais: contribuições para uma agenda brasileira. Belo Horizonte: ABEP, p. 107-122, 2012.

CUI, L., SHI, J. Urbanization and its environmental effects in Shangai, China. Urban Climate. V.2, p.1-15, 2012.

HORBACH, J., RAMMER, C., RENNINGS, K. Determinantes da Ecoinovação por tipo de impacto ambiental: o papel da pressão regulatória, da alavancagem tecnológica e do fator mercado. In: ARRUDA, C., CARVALHO, F. Inovações ambientais: políticas públicas, tecnologias $e$ oportunidades de negócios. Rio de Janeiro: Elsevier, 2014, cap. 3, p. 67- 100.

HOPE, K.R. Urbanization and economic development in the third world: an overview. Cities, V.3 N. 1, 41-57, 1986.

IDS. Indicadores de Desenvolvimento Sustentável. Estudos \&Pesquisas. Informação Geográfica 7. Brasil 2010.

Disponível em: $<$ http://www.ibge.gov.br/home/geociencias/recursosnaturais/ids/ids2010.pdf $>$. Acesso em: 20 de julho de 2012.

JOHNSON, R., WICHERN, D. Applied Multivariate Statistical Analysis. 5th Ed. Englewood Clifs: Prentice Hall, 2002.

KALNAY, E., CAI, M. Impact of urbanization and land-use change on climate. Nature, 423, 528$531,2003$.

KEMP, R., SOETE, L. The greening of technological progress: an evolutionary perspective. Futures. V. 24, n. 5, 1992.

LEVESQUE, B. Contribuição da nova sociologia econômica para repensar a economia no sentido do desenvolvimento sustentável. Revista Administração de Empresas. Vol. 47. N. 2. São Paulo, 2007.

LIPIETZ, A. O capital e seu espaço. Editora Nobel, São Paulo. 1987.

MANLY, F. J. B. Métodos Estatísticos Multivariados: uma introdução; tradução Sara Ianda Carmona, - 3.ed - Porto Alegre: Bookman , 2008. 
MARTINE, G., TORRES, H., MELlO, L. F. de. Cultura do Consumo e desenvolvimento econômico na era de mudanças climáticas. In: MARTINE, G. (Ed.) OJIMA, R., BARBIERI, A. F., CARMO, R. L. (Co-Orgs.) População e Sustentabilidade na era das mudanças ambientais globais: contribuições para uma agenda brasileira. Belo Horizonte: ABEP, p. 19-31, 2012.

MINGOTI, S. A. Análise de dados através de métodos de estatística multivariada: uma abordagem aplicada. Belo Horizonte, Editora UFMG. 2007. 295p.

NAKANO, K., CUNHA, J. M. P. A Rio+20 e os desafios da crise urbana. In: MARTINE, G. (Ed.) OJIMA, R., BARBIERI, A. F., CARMO, R. L. (Co-Orgs.) População e Sustentabilidade na era das mudanças ambientais globais: contribuições para uma agenda brasileira. Belo Horizonte: ABEP, p. 163-174, 2012.

QUEIROZ, B. L., BARBIERI, A. F. Vulnerabilidade às mudanças climáticas e adaptação no Brasil. . In: MARTINE, G. (Ed.) OJIMA, R., BARBIERI, A. F., CARMO, R. L. (Co-Orgs.) População e Sustentabilidade na era das mudanças ambientais globais: contribuições para uma agenda brasileira. Belo Horizonte: ABEP, p. 71-81, 2012.

QUEIROZ, B. L.; BARBIERI, A. Os potenciais efeitos das mudanças climáticas sobre as condições de vida e a dinâmica populacional no Nordeste Brasileiro. In: HOGAN, Daniel J.; MARANDOLA Jr, Eduardo (org.). População e mudança climática: Dimensões humanas das mudanças ambientais globais. Campinas - Brasília: NEPO/UNICAMP - UNFPA, 2009, p. 159-186.

SANTOS, M. Técnica, Espaço, Tempo. Globalização e meio técnico-científico informacional. 1994

TORRES, H. G., SYDENSTRICKER-NETO, J. Por uma periferia sustentável. In: MARTINE, G. (Ed.) OJIMA, R., BARBIERI, A. F., CARMO, R. L. (Co-Orgs.) População e Sustentabilidade na era das mudanças ambientais globais: contribuições para uma agenda brasileira. Belo Horizonte: ABEP, p. 123-186, 2012.

VINHA, V. Polanyi e a Nova Sociologia Econômica: uma aplicação contemporânea do conceito de enraizamento social. Revista Econômica, v.3, n. 2, p. 207-230, 2001.

WCED. World Commission on Environment and Development. Our commom Future. Oxford and New York: Oxford University Press, 1987.

WEISS, M. A. Metropolitan Economic Strategy: The key to prosperity. Global Urban Development. Volume $1 . \quad$ Issue 1.2005 .2 Disponível em: $<$ http://www.globalurban.org/Issue1PIMag05/Weiss\%20PDF.pdf $>$. Acesso em: 24 de julho de 2012. 